\title{
First decade of clinical trials and published studies with mesenchymal stromal cells from umbilical cord tissue
}

\author{
Pedro S Couto ${ }^{1,2}$, Gocha Shatirishvili³, Alexey Bersenev ${ }^{4}$ \& Frances Verter*,1 \\ ${ }^{1}$ Parent's Guide to Cord Blood Foundation, Brookeville, MD 20833, USA \\ ${ }^{2}$ Department of Biochemical Engineering, University College London, London WC1E 7JE, UK \\ ${ }^{3}$ Geocord Cord Blood Bank, Tbilisi 0186, Georgia \\ ${ }^{4}$ Advanced Cell Therapy Laboratory at Yale - New Haven Hospital, Yale University, New Haven, CT 06520, USA \\ *Author for correspondence: fverter@his.com
}

\begin{abstract}
Aim: This is the first analysis of both clinical trials and published studies that employ umbilical cord mesenchymal stromal cells, for the decade 2007-2017. Materials \& methods: Searching international databases, we found 178 registered trials and 98 publications. Results: Among the registered clinical trials, $20 \%$ have resulted in publications so far. Among the publications, $18 \%$ report safety and $74 \%$ report some form of improvement. Between 36 and $45 \%$ of the publications do not report aspects of the cell manufacturing, including isolation method, culture medium or number of culture passages. Conclusion: Analyses that link trials with publications can elucidate factors that promote study completion and publication. More full disclosure of cell manufacturing is needed to evaluate the efficacy of mesenchymal stromal cell isolated from umbilical cord tissue (UC-MSC) products.
\end{abstract}

First draft submitted: 27 December 2018; Accepted for publication: 27 March 2019; Published online: 9 May 2019

Keywords: cell therapy $\bullet$ clinical trial $\bullet$ manufacturing $\bullet$ mesenchymal stromal cells (MSC) • umbilical cord tissue

In 2006 the International Society of Cell Therapy (ISCT) published criteria for the definition of mesenchymal stromal cells (MSCs) [1]. A worldwide review of all clinical trials in the field of regenerative medicine during the two decades 1992-2012 showed that most of the increase in novel trials since 2006 has been due to trials using MSCs for multiple indications [2]. In 2016, a review of the publications from those 1992-2012 trials found that only $37.4 \%$ of the regenerative medicine trials were completed, and among the trials with MSC, only $21.9 \%$ were later published [3]. To the best of our knowledge, that was the only prior research to compare registered clinical trials versus subsequent publications in the field of cell therapy.

We published the first review of advanced cell therapy performed with cells from perinatal sources, covering the first decade of that field (2005-2015) [4]. We found that the majority of growth in that arena has been from trials that rely on the action of MSC isolated from perinatal blood or tissues.

In this article we focus more narrowly on the first decade (2007-2017) of human clinical studies that employ MSCs isolated from umbilical cord tissue (UC-MSCs). We have chosen to focus on UC-MSCs because they are both the dominant perinatal cell type in clinical trials, and since 2016 umbilical cord tissue is the dominant source of MSC for all MSC clinical trials [4]. Our first goal is to compile a worldwide comparison of the registered clinical trials versus journal publications that employ UC-MSC to perform regenerative medicine.

A second goal of this article is to review the UC-MSC manufacturing methods that were reported in the published clinical studies, to the extent that this is possible. There is a body of ongoing research that examines the immunomodulatory behavior of MSC to explain their mechanism of action in human clinical studies [5-7]. These are important questions at the cellular level, but we wish to add insight on pragmatic bioengineering questions: What is the impact of product manufacturing on the clinical outcome? Only by making a thorough review of the processing methods reported in the published studies can we begin to answer these questions, or determine if it is possible to answer these questions. Future
Medicine 
Table 1. Geographic regions of UC-MSC trials and publications.

\begin{tabular}{|lll|}
\hline Geographic region & Registered trials (\%) & Published papers (\%) \\
\hline China & 76 & 93 \\
\hline Rest of Asia & 4 & 3 \\
\hline EU and Middle East & 9 & 2 \\
\hline Central and South America & 6 & 0 \\
\hline USA and Canada & 5 & 2 \\
\hline US-MSC: Umbilical cord-mesenchymal stromal cell. & & \\
\hline
\end{tabular}

\section{Materials \& methods}

The time period covered by this study is from the beginning of 2007 through the end of 2017.

All of the clinical trials and published reports in the study time frame that utilized UC-MSC qualify as advanced cell therapy. The definition of 'advanced cell therapy' is any therapy in which the cells are more than minimally manipulated and/or their action is not homologous, as established by the EMA and consistent with the US FDA definition of Section $351 \mathrm{HCT} / \mathrm{P}[8,9]$.

Clinical trials utilizing UC-MSC were manually compiled from over a dozen clinical trial registries worldwide. The list of registries can be found in Table 1 of our previous study of all trials with perinatal cells [4]. Published reports of clinical studies that employ UC-MSC were manually compiled from the National Library of Medicine Medline worldwide database of publications [10]. For both trials and publications, we searched these English keywords, independently: 'Wharton's Jelly', 'umbilical cord tissue', 'umbilical cord', 'umbilical tissue', 'stromal' and 'mesenchymal'. Among the publications we included case reports and conference posters but excluded multiple publications about the same study. All qualifying trials and publications were reviewed by at least two scientists to confirm that they met the selection criteria.

Please note that the number of trials per year in this study differs from the UC-MSC count in Table 3 of our previous study [4], because the previous table only listed trials that used UC-MSC exclusively without any other cell type; whereas, this study includes any trial that employs UC-MSC.

For the purposes of our study, we use the term 'trials' to describe clinical studies that are listed on one of the clinical trial registries that are aggregated by the WHO. If a clinical study was not listed on a registry, we simply call it a 'study'. Any trial or study that was published in a peer-reviewed journal is called a 'publication'. It is important to make these terminology distinctions clear because some authors search publications but call them trials [11,12].

In order to link trials with publications of their results, the following search strategies were used: the simplest approach was to query PubMed for publications that contain the trial registration number. In practice, many publications did not cite any trial and the search for an associated trial was based on a detailed comparison of all the study parameters: the lead scientists, the sponsoring institution, the clinical location, the specific indication, the time frame, and the study design including number of patients and therapy arms. As before, links between trials and publications were reviewed independently by at least two scientists for confirmation.

All the information about the manufacturing methods reported to prepare UC-MSC for human clinical use was compiled from the publications. The process of registering a clinical trial does not require any description of the preparation of the drug or cell therapy that is administered in the trial. By comparison it is reasonable and customary to include this information as part of the Materials \& methods section of a cell therapy publication.

\section{Results}

After our screening process, we identified 178 registered clinical trials that employ UC-MSC and 98 publications about cell therapy that employ UC-MSC, for the years 2007-2017. For the registered clinical trials, this decadal number is the same as a cumulative number, because our previous analysis of registered perinatal trials did not found any UC-MSC trials prior to 2007 [4]. Another previous review of clinical trials that employ UC-MSC found 109 trials in the ClinicalTrials.gov registry alone for the years 2009 through January 2017 [13]; whereas, we found 117 trials in ClinicalTrials.gov for this time period. A previous review of publications that employ UC-MSC found 93 full articles published cumulatively through 1 August 2017 [11]; whereas, we counted 98 publications from 2007 through the end of 2017. We have six more publications than the prior review, and we excluded one of these as a duplicate publication of the same results. 
Figure 1. Relationship between umbilical cord-mesenchymal stromal cell trials versus publications 2007-2017.
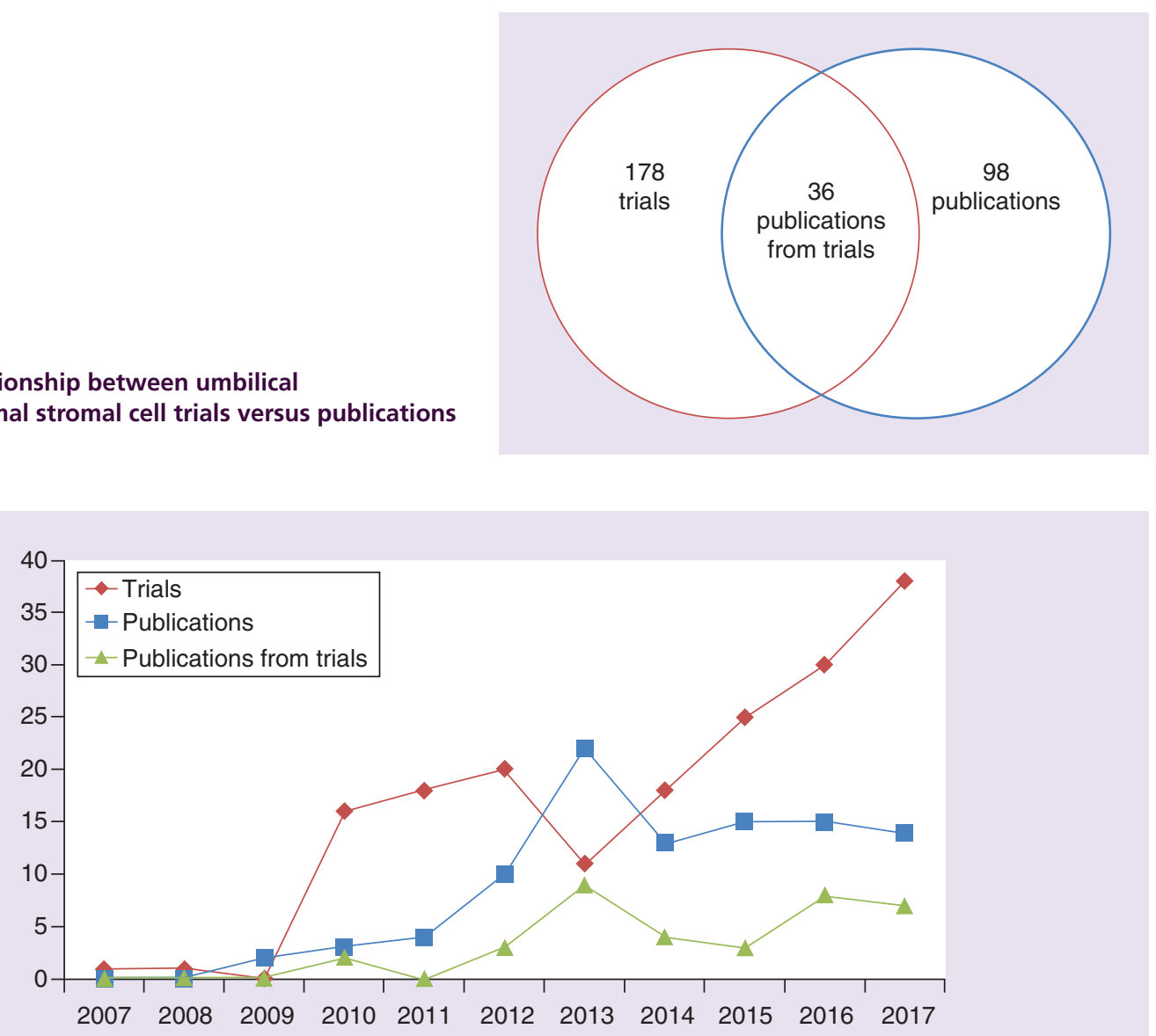

Figure 2. Timeline of umbilical cord-mesenchymal stromal cell trials and publications by year.

To the best of our knowledge, there is only one previous study in the field of cell therapy that asked how many clinical trials go to completion and publication [2,3]. That study found that out of 1052 'novel' cell therapy trials registered over the two decades 1992-2012, by 4 years later $37.4 \%$ had been completed [3]. For our 178 UC-MSC trials registered over the decade 2007-2017, less than 1 year later on 27 October 2018, we found that 16\% were listed with status 'completed', 43\% were still recruiting or ongoing without recruiting, 37\% had status unknown and $4 \%$ had been terminated or withdrawn. The previous study that linked trials to publications found that out of 403 clinical trials that employed MSC from any source, 4 years later only $21.9 \%$ were published [3]. We found that by the end of 2017,36 or $20 \%$ of clinical trials registered 2007-2017 that employ UC-MSC have resulted in publications, as displayed in Figure 1.

We performed a time analysis in Figure 2 that displays worldwide totals for each year: the number of UC-MSC trials registered, the number of UC-MSC publications and the number of publications from registered clinical trials. Over the 5 years 2013-2017, the number of trials per year has been rising; whereas, the number of publications per year is nearly constant and the fraction of publications from trials does not vary greatly. It should be noted that publications which come from clinical trials are not published until at least a year after the trial registration. This may explain the observations that after a drop in clinical trials during 2013 there is a drop in publications during 2014. In general, if the trends in this graph continue they suggest a growing disconnect between ongoing research and outcomes reporting in the UC-MSC field.

The phases of both the UC-MSC trials and the UC-MSC publications are dominated by early research. Figure 3 displays the number of trials as a function of phase, plus the distribution by phase of publications from trials and publications that are not from trials. Nearly half of the trials, $47 \%$, are in Phase I/II. The total number of publications also peak at Phase I/II. However, the publications fall into two distinct camps: among publications which came from clinical trials, $75 \%$ of 36 publications are Phase I/II or II. By comparison, the publications that 


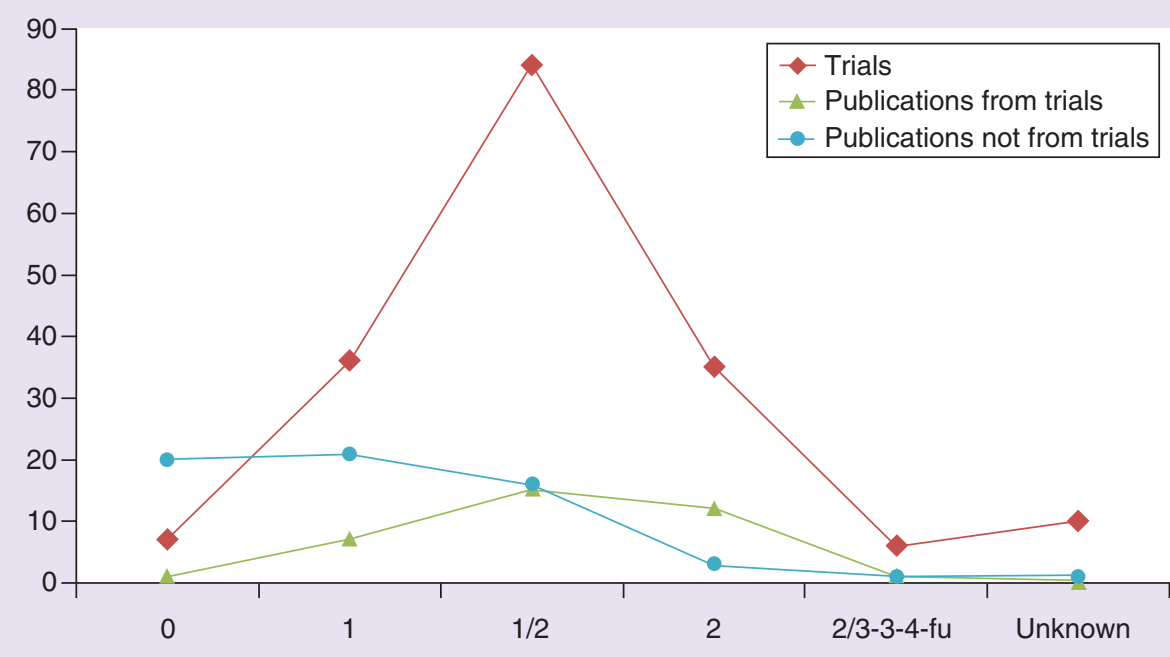

Figure 3. Plotted against study phase, the number of trials, publications from trials and publications not from trials.

are not associated with trials are often case reports or descriptions of pilot studies, with $66 \%$ of 62 publications falling at Phase 0 to I.

The geographic regions where these clinical trials and publications were located are listed in Table 1 . None of the trials or publications are multinational, so all could be assigned to one region. The vast majority of the registered trials and publications originating from China, at 76 and 93\%, respectively. During the years covered by this study, Chinese regulations did not require researchers to register a clinical trial when performing a human clinical study [14]. Therefore our detailed procedure for finding trials associated with the publications was necessary. Moreover, we found that certain prominent researchers took the lead on multiple trials and multiple publications in the same medical specialty, which made it even more challenging to match up their trials and their publications. We were able to find Chinese publications via their English abstracts.

Due to their immunomodulatory properties and multilineage differentiation ability in vitro [5-7], MSCs have been tested to treat a wide variety of medical conditions. In Table 2 we break down the indications treated in both the trials and publications by groups of clinical conditions. We have followed the definitions of clinical groups established by a previous thorough review of UC-MSC publications, since $94 \%$ of our 98 publications are previously covered in their review [11]. The previous review already discusses the breakdown of these publications in terms of route of administration, use of multiple doses, cell dose per injection, patient age and cell preparation in GMP conditions [11].

Given the wide variety of medical conditions treated in these 98 publications, it is not surprising that there is also a wide variety of UC-MSC doses and routes of administration. Standard dosing regimens have not yet been established for most cell and gene therapies with MSC, and none of these studies explained their choice of dose. As a first effort to understand relationships between dose and delivery, we decided to compare the doses delivered by systemic infusions versus local injections. In the systemic infusion category we included 62 publications that employed intravenous and intra-arterial delivery. The local injection group held 24 publications with delivery methods including intrathecal, intra-articular, intramyocardial, transcoronary, hepatic artery, transvitreal or surgery followed by local administration with the help of scaffolds. There were seven publications that employed more than one mode of delivery and contributed to both groups; whereas, 12 publications did not disclose their route of delivery.

The median total cell dose in these publications was 18.75 million for local delivery versus 80 million for systemic infusion. Figure 4 is a histogram of the cell doses for the two types of delivery route. The range of total cell doses extended from 0.5 million cells to more than 800 million cells for both local injections and systemic infusions, but large doses occur primarily for systemic infusions. The existence of very low cell doses in both groups partly reflects the fact that we elected to include any studies that employ UC-MSC, even if they are in addition to other cell types. In the future, it might be preferable to treat intravenous doses as a separate category. Animal studies have 
Table 2. Indications treated by umbilical cord-mesenchymal stromal cell trials and publications.

\begin{tabular}{|c|c|c|c|c|}
\hline Clinical condition group & Diagnoses in publications & \# Trials & \# Publications & \# Pubs. from trials \\
\hline Neurologic & $\begin{array}{l}\text { - Amyotrophic lateral sclerosis } \\
\text { - Autism } \\
\text { - Ataxia (hereditary, spinocerebellar) } \\
\text { - Cerebral palsy } \\
\text { - Hypoxic ischemic encephalopathy } \\
\text { - Multiple sclerosis (progressive, relapsing-remitting) } \\
\text { - Neuromyelitis optica } \\
\text { - Radial nerve injury } \\
\text { - Radiation myelitis } \\
\text { - Spinal cord injury } \\
\text { - Stroke (hemorrhagic, ischemic and chronic) } \\
\text { - Traumatic brain injury } \\
\text { - Vascular dementia }\end{array}$ & 40 & 25 & 11 \\
\hline Hematologic & $\begin{array}{l}\text { - Aplastic anemia } \\
\text { - Graft versus host disease (acute, steroid-resistant) } \\
\text { - Hemorrhagic cystitis after stem cell transplantation } \\
\text { - Leukemia (high risk, lymphocytic, myeloid, refractory, relapsed) } \\
\text { - Non-Hodgkin's lymphoma } \\
\text { - Thrombocytopenia }\end{array}$ & 13 & 19 & 1 \\
\hline Immunologic & $\begin{array}{l}\text { - Systemic lupus erythematosus (diffuse alveolar hemorrhage, } \\
\text { nephritis, refractory) } \\
\text { - Hemorrhagic cystitis } \\
\text { - HIV infection } \\
\text { - Rheumatoid arthritis } \\
\text { - Ulcerative colitis }\end{array}$ & 23 & 15 & 6 \\
\hline Liver & $\begin{array}{l}\text { - Cirrhosis (autoimmune-induced, decompensated, hepatitis B, } \\
\text { primary biliary) } \\
\text { - Ischemic-type biliary lesions } \\
\text { - Transplant rejection }\end{array}$ & 20 & 11 & 5 \\
\hline Cardiac & $\begin{array}{l}\text { - Acute myocardial infarction } \\
\text { - Chronic total occlusion } \\
\text { - Ischemic cardiomyopathy } \\
\text { - Systolic heart failure }\end{array}$ & 10 & 7 & 2 \\
\hline Endocrine & $\begin{array}{l}\text { - Diabetes (Type I, Type II) } \\
\text { - Diabetic foot ulcer } \\
\text { - Ketoacidosis }\end{array}$ & 16 & 7 & 6 \\
\hline Musculoskeletal & $\begin{array}{l}\text { - Avascular necrosis of femoral head } \\
\text { - Becker muscular dystrophy } \\
\text { - Bone nonunion (fractured, infected) } \\
\text { - Duchenne muscular dystrophy } \\
\text { - Osteonecrosis of femoral head }\end{array}$ & 18 & 7 & 2 \\
\hline Pulmonary & $\begin{array}{l}\text { - Idiopathic pulmonary fibrosis } \\
\text { - Pulmonary injury from paraquat poisoning } \\
\text { - Pulmonary infection secondary to haploidentical stem cell } \\
\text { transplantation }\end{array}$ & 10 & 3 & 0 \\
\hline Dermatologic & $\begin{array}{l}\text { - Psoriasis vulgaris } \\
\text { - Stevens-Johnson syndrome (drug induced) } \\
\text { - Cesarean scar defect }\end{array}$ & 11 & 3 & 2 \\
\hline Opthalmologic & - Retinitis pigmentosa & 7 & 1 & 1 \\
\hline Other & & 10 & 0 & 0 \\
\hline Totals & & 178 & 98 & 36 \\
\hline
\end{tabular}

shown that when MSC are administered intravenously, they quickly migrate to the lung parenchyma and become trapped there; whereas, intra-arterial or local delivery of cells can avoid this fate and reach the site of injury [15-18].

Next we examined parameters of the UC-MSC manufacturing process in 98 publications. A previous study reviewed the cell manufacturing for MSC isolated from bone marrow (BM-MSC) in 47 publications [12]. We will compare our statistics to theirs where appropriate. The manufacturing parameters for which we have gathered data are: UC-MSC isolation method, use of fetal bovine serum (FBS) and number of passages during UC-MSC culture.

The method by which UC-MSCs were isolated from umbilical cord tissue was not described in 35 of the publications. Among the publications that did report their isolation method, 39 used the explants method and the remaining 24 used an enzymatic method. In explants method of UC-MSC isolation, pieces of minced cord tissue are plated with growth media in a plastic tissue culture dish until UC-MSCs, which are plastic-adherent 


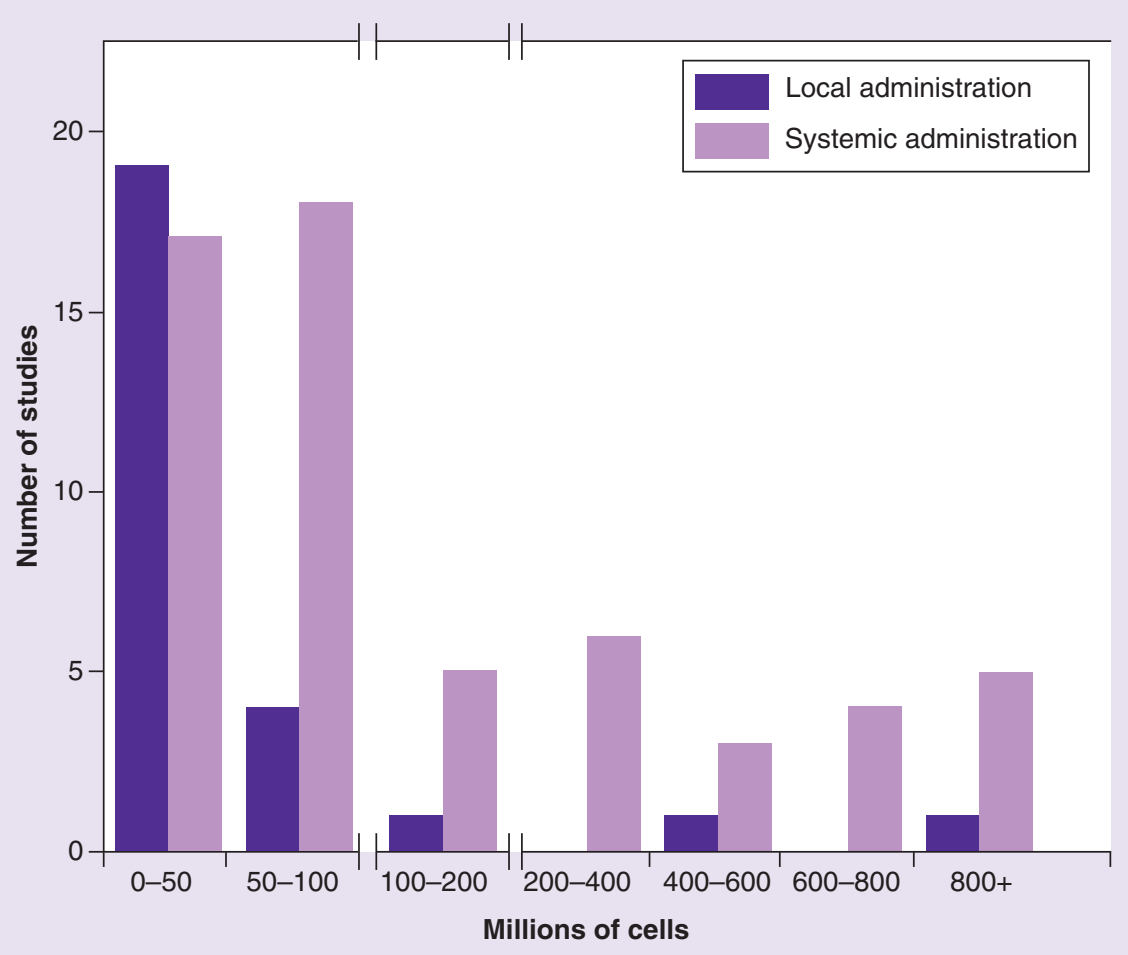

Figure 4. Total cell dose in umbilical cord-mesenchymal stromal cell publications for local versus systemic routes of administration. Whenever the patients received multiple doses, we multiplied the individual dose by the number of doses so that the statistics reflect total doses. Whenever the dose was given in units of cells per kg of patient weight, we converted to numbers of cells by assuming the weight of all patients was $80 \mathrm{~kg}$. Breaks in the horizontal axis were used every time the scale changed. The median cell dose for local administration was 18.75 million; whereas, for systemic infusion the median was 80 million.

cells, are seen proliferating attached to the dish. The plated cells may go through one or more culture passages, as described below. A small amount of enzymes is used to separate the UC-MSC from the dish surface. By comparison, enzymatic methods of UC-MSC isolation rely on larger quantities of enzymes to break down the collagen fibers of the cord tissue and release the UC-MSC. Some of the publications that used the digestion method to isolate UC-MSC then proceeded to a plate culture step to expand the quantity of MSC.

In the process of tabulating the isolation method used in each publication, we noticed that researchers in different fields of clinical practice tend to opt for different UC-MSC isolation methods, as illustrated in Figure 5. The biggest group is that of neurologic publications, where researchers strongly favor explants over digestion at 18 to five (with two publications in which the isolation method is unknown). By comparison, in hematology, all nine publications that describe their isolation method used digestion (ten publications with unknown isolation methods). The immunologic publications also favor explants over digestion at six to three (six publications unknown). Liver disease is the opposite of hematology and all of the nine publications that describe their isolation method used explants (two publications unknown). Finally, cardiac and endocrine publications are both evenly split between two explants, two digestion and three publications unknown in each case.

Different clinical studies that employ UC-MSC may rely on different mechanisms of action for their cell therapy. For example, an immunologic study might rely on the immunomodulatory properties of UC-MSC, whereas a cardiac study may seek to promote angiogenesis. Ultimately, the UC-MSC cell isolation and expansion should be optimized for the desired clinical effect. At present there is no industry consensus on an optimum isolation method for UC-MSC; however, it has been reported that enzymatic digestion reduces the proliferation and changes the phenotype of UC-MSC [19-21].

Another important aspect to consider during the UC-MSC cell manufacturing process is the medium formulation. FBS has a long history of use in cell culture, but it has significant disadvantages for clinical applications. One 


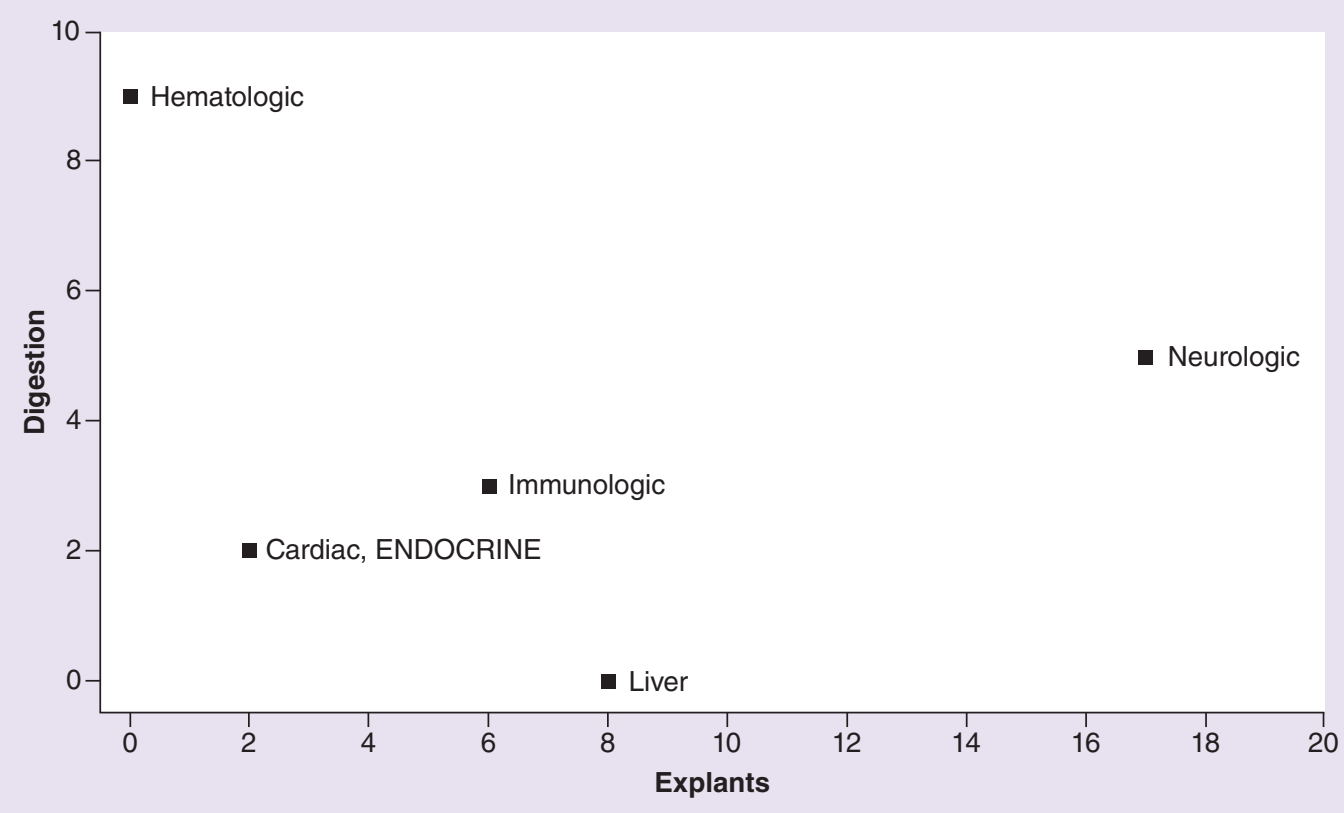

Figure 5. Cell isolation methods of umbilical cord-mesenchymal stromal cell publications plotted by indication for use. The number of publications that used explants isolation is plotted on the $X$ axis, versus the number of publications that used digestion on the $Y$ axis, for those six diagnosis groups that had four or more publications with known isolation method.

is that differences between batches of serum can lead to variability in the final cell therapy product, and more importantly FBS carries the risk of contamination with xenogenic disease [22]. Among the 98 UC-MSC publications, 44 did not describe their medium formulation, but 40 publications reported using FBS as part of the cell growth medium, and only 14 publications clearly stated that they used alternatives to FBS such as human platelet lysate or serum free media. Whereas we found that FBS was definitely used in $41 \%$ of reporting UC-MSC publications 2007-2017, an earlier review found it used in 77\% of reporting BM-MSC publications 2007-2013 [12]. Those researchers who plan to apply for market approval of their UC-MSC therapy will have to reconcile their choice of growth medium with the regulatory requirements of their environment.

An important variable in the preparation of therapies with MSC from any source is the number of passages to which the MSC were cultured prior to clinical administration. While the population doubling is the most accurate indicator of how many expansion cycles the cells went through, in practice laboratory scientists report the 'passages' which count every time that an adherent cell population is detached and plated again in tissue culture flasks. Regardless of the UC-MSC isolation method, it is common practice for laboratories to culture UC-MSC through at least one or two passages to reach the doses suggested for clinical applications. At any laboratory where the UC-MSC product is prepared in advance, it will be cryopreserved. When the UC-MSCs are thawed for clinical use, they may or may not undergo a second culture phase before they are delivered. Hence when publications report the number of passages in their UC-MSC product, they should report the sum of these two culture phases. Only two of our publications stated that they used fresh cells with no passages.

The number of passages in the final UC-MSC therapy product is important because it has been reported that after high numbers of passages MSC lose their potency, which can result in the loss of therapeutic efficacy and the failure of clinical trials $[23,24]$. It has also been reported that cryopreservation might have a negative impact on the properties of MSC [25-27]. In Figure 6 we show a histogram of reported passage number in the 98 UC-MSC publications. While $45 \%$ of the publications did not report the passage number, the number is between P1 and P5 for $83 \%$ of the reporting UC-MSC publications 2007-2017, which is similar to an earlier review of BM-MSC manufacturing which found P1-P5 for 71\% of reporting BM-MSC publications 2007-2013 [12]. 


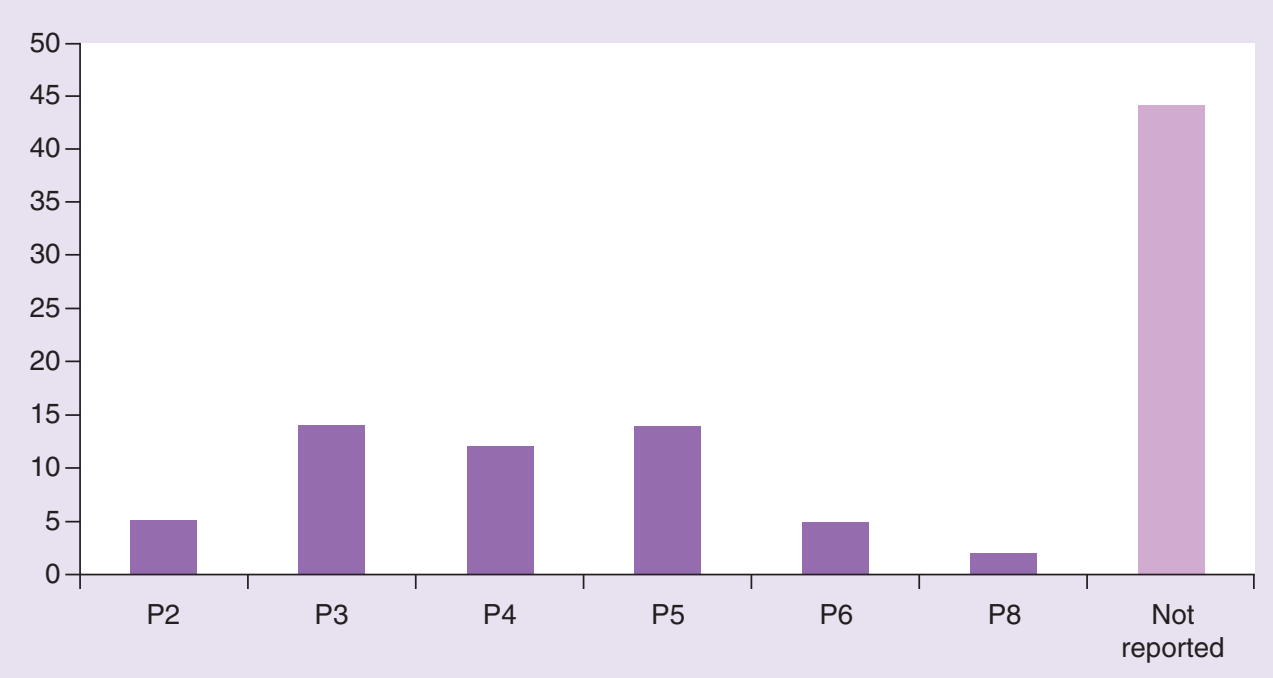

Figure 6. Number of cell culture passages in umbilical cord-mesenchymal stromal cell publications. When creating this histogram, if a publication reported passage number $X$ to $Y$, it was binned as $Y$.

\section{Discussion}

Cell and gene therapy is widely regarded as a new frontier of medicine [28]. In this study we have kept a narrow focus on the cell type UC-MSC, going in depth to compare the registered clinical trials versus the published outcomes and also the specific cell manufacturing in the published studies. Our findings are illustrative of the ramifications that this type of comparison can have for different stake holders in the cell therapy field.

One stakeholder of the cell therapy field are the patients. It has been noted that direct-to-consumer marketing of unproven stem cell therapies can influence trial registration in this field [29]. When compiling our data, we noticed that a single for-profit clinic had listed five trials on ClinicalTrials.gov during a 1 year period from 2013 to 2014, but none had been published by the close of our study at the end of 2017. This prompted us to review the sponsors of both the UC-MSC trials and the UC-MSC publications to see what fractions had received financial support from academic institutions versus industry. For these purposes we define 'academia' as universities, hospitals and medical research organizations; whereas, we consider for-profit companies developing pharmaceutical products to be 'industry'. We found that $76 \%$ of the 178 UC-MSC clinical trials were sponsored by academic institutions or by collaborations between industry and academia. The authors of the 98 UC-MSC publications were affiliated with academic institutions in $95 \%$ of the publications, and they explicitly acknowledged grant support in $60 \%$ of the publications. Hence we are reassured that a strong majority of listed clinical trials and publications in the UC-MSC field are sponsored wholly or in part by institutions that clearly support legitimate research.

Another set of stakeholders in the UC-MSC therapy field are the laboratories involved in the UC-MSC manufacturing process. These include a mixture of small research laboratories and large contract manufacturers. We found there may be a communication disconnect between the laboratories preparing UC-MSC and the clinicians administering UC-MSC therapy. A significant fraction of clinical publications fail to describe the UC-MSC cell manufacturing process, with 36\% not specifying the UC-MSC isolation method, $45 \%$ not specifying the medium formulation in the UC-MSC culture and $45 \%$ not stating the number of culture passages of the UC-MSC in the final therapeutic product. We feel there should be improved education for clinicians that practice cell therapy, so that they have greater appreciation that UC-MSC products are not all the same, and the manufacturing may influence the quality of the final UC-MSC product.

Another set of stakeholders in the cell therapy field are the researchers who run clinical studies and publish their outcomes. There is a well-known phenomenon that medical research which reports positive results is much more likely to be published [3]. In the field of cell therapy specifically, a previous review article found that 1052 trials in regenerative medicine resulted in 333 publications, where $88.8 \%$ of those publications reported that the intervention was safe and $67.3 \%$ reported positive outcomes even though the majority of the trials were early phase [3]. We found a similar trend towards positive outcomes in our 98 publications about therapies that employ 
UC-MSC. After carefully reviewing each publication, we would characterize $74 \%$ as reporting positive outcomes. We tried not to over-interpret the keywords 'safe' and 'effective' when they were used by authors whose primary language is not English. Nonetheless most of the publications report positive outcomes in the sense that the outcome was improved against the control arm in the study, or it was improved in retrospective comparison to the baseline of expected outcomes for the medical condition. Often the authors supported their claims with statistical significance levels from Student's t-test. In our survey an additional $18 \%$ of publications reported that the UC-MSC intervention was safe, and any patient deaths in these studies were usually attributed to their underlying disease. Overall, we found that $93 \%$ of our publications reported safe or positive outcomes.

Another stakeholder in the cell therapy field are the sponsors of clinical studies. A previous review of 297 publications from cell therapy studies found that positive efficacy was more likely to be reported from trials of novel cell therapies that were funded by industry versus public research institutions, at 77.2 versus $67.2 \%$ [3]. In our smaller sample we actually saw the opposite trend. Among our 98 UC-MSC publications only three explicitly reported that they did not see improvement or that the procedure was not safe, and two of those were among our five publications completely funded by industry. We think the impact of industry versus grant funding of cell and gene therapy research should be examined carefully in further studies. We have noticed that sometimes a registered trial that was clearly funded by a corporate sponsor is published with the appearance of academic research, so that only studies which link trials to their later publications can fully discriminate any correlations in outcome reporting versus funding source.

\section{Conclusion}

To the best of our knowledge, this study is the first to link clinical trials that employ UC-MSC with published results. For the time period 2007-2017, we found 178 registered clinical trials and 98 publications. By the end of 2017, 20\% of the UC-MSC trials had resulted in 36 publications. The remaining 62 publications came from clinical studies that were never listed on trial registries. A limitation of this study is that published results may not appear until at least a year after the conduct of a trial. Since $38 \%$ of our trials were registered during the final 2 years of our study decade, our statistics on rates of trial completion and publication should be regarded as preliminary.

Our experience is a cautionary tale about the difficulty of linking trials with publications on an international scale. There is a popular image in the medical field that clinical trials and publications are connected by a pipeline, where registered trials go in at the beginning and publications come out at the end. That image is only valid in those countries that require a trial to be registered when conducting a clinical study. Even then, safety studies usually do not require a trial registration, unless the researchers aim to publish in a journal that follows the requirements of the International Committee of Medical Journal Editors [30,31]. We found that in the UC-MSC therapy field, a better image of the connection between trials and publications is a Venn diagram.

We attempted to identify trends between cell manufacturing and clinical outcome in the arena of UC-MSC therapy. We found that there is a little variation among the outcomes, with the overwhelming majority of the publications reporting positive outcomes. We also found that the cell manufacturing data is often missing from published reports. Given the lack of variation in the outcomes and the lack of data about manufacturing, we were not able to identify any trends between outcomes and manufacturing.

Going forward, we call for all publications in the arena of UC-MSC therapy to explicitly characterize the preparation of the cells and the release criteria of UC-MSC products in clinical applications.

\section{Financial \& competing interests disclosure}

The authors have no relevant affiliations or financial involvement with any organization or entity with a financial interest in or financial conflict with the subject matter or materials discussed in the manuscript. This includes employment, consultancies, honoraria, stock ownership or options, expert testimony, grants or patents received or pending, or royalties.

No writing assistance was utilized in the production of this manuscript. 
Open access

This work is licensed under the Attribution-NonCommercial-NoDerivatives 4.0 Unported License. To view a copy of this license, visit http://creativecommons.org/licenses/by-nc-nd/4.0/

\section{Summary points}

- A total of 178 clinical trials that employ mesenchymal stromal cells isolated from umbilical cord tissue (UC-MSC) were registered 2007-2017.

- A total of 98 clinical studies that employ UC-MSC were published 2007-2017.

- Among the trials registered 2007-2017, 16\% had status completed by 27 Oct 2018.

- Among the publications 2007-2017, 20\% came from the registered clinical trials.

- The therapy was reported to be safe in $18 \%$ of the publications.

- Another $74 \%$ of the publications reported some form of improvement from the UC-MSC therapy.

- Academic grant support was acknowledged by $60 \%$ of the publications.

- The UC-MSC isolation method was not reported in $36 \%$ of the publications.

- The UC-MSC growth medium formulation was not reported in $45 \%$ of the publications.

- The number of culture passages of the final UC-MSC product was not reported in $45 \%$ of the publications.

\section{References}

1. Dominici M, Le Blanc K, Mueller I et al. Minimal criteria for defining multipotent mesenchymal stromal cells. The International Society for Cellular Therapy position statement. Cytotherapy 8(4), 315-317 (2006).

2. Li MD, Atkins H, Bubela T. The global landscape of stem cell clinical trials. Regen. Med. 9(1), 27-39 (2014).

3. Fung M, Yuan Y, Atkins H, Shi Q, Bubela T. Responsible Translation of Stem Cell Research: an assessment of clinical trial registration and publications. Stem Cell Rep. 8(5), 1190-1201 (2017).

4. Couto PS, Bersenev A, Verter F. The first decade of advanced cell therapy clinical trials using perinatal cells (2005-2015). Regen. Med. 12(8), 953-968 (2017).

5. Nauta AJ, Fibbe WE. Immunomodulatory properties of mesenchymal stromal cells. Blood 110(10), 3499-506 (2007).

6. Caplan AI, Correa D. The MSC: an injury drugstore. Cell Stem Cell. 9(1), 11-15 (2011).

7. Bernardo ME, Fibbe WE. Mesenchymal stromal cells: sensors and switchers of inflammation. Cell Stem Cell 13(4), 392-402 (2013).

8. Regulation (EC) No 1394/2007 of the European Parliament and of the Council of 13 November 2007 on advanced therapy medicinal products and amending Directive 2001/83/EC and Regulation (EC) No 726/2004 (2007). http://ec.europa.eu/health/sites/health/files/files/eudralex/vol-1/reg_2007_1394/reg_2007_1394_en.pdf

9. US FDA. Accessed 27 Oct. 2018 FDA regulation of human cells, tissues, and cellular and tissue-based products (HCT/P's) product list. www.fda.gov/BiologicsBloodVaccines/TissueTissueProducts/RegulationofTissues/ucm150485.htm

10. PubMed ${ }^{\circledR}$ MD, USA: National Library of Medicine (US), Specialized Information Services Division. (2008). www.ncbi.nlm.nih.gov/pubmed

11. Can A, Celikkan FT, Cinar O. Umbilical cord mesenchymal stromal cell transplantations: a systemic analysis of clinical trials. Cytotherapy 19(12), 1351-1382 (2017).

12. Ikebe C, Suzuki K. Mesenchymal stem cells for regenerative therapy: optimization of cell preparation protocols. Biomed. Res. Int. 2014, 951512 (2014).

13. Davies J, Walker JT, Keating A. Concise Review: Wharton's Jelly: the rich but enigmatic, source of mesenchymal stromal cells. Stem Cells Trans. Med. 6(7), 1620-1630 (2017).

14. Li Y, Wang B, Zhang Y, Verter F, Gu N. Regulations on cell therapy products in china (2019) [Unpublished Manuscript].

15. Harting MT, Jimenez F, Xue H et al. Intravenous mesenchymal stem cell therapy for traumatic brain injury. J. Neurosurg. 110(6), 1189-1197 (2009).

16. Park SE, Lee NK, Lee J et al. Distribution of human umbilical cord blood-derived mesenchymal stem cells in the Alzheimer's disease transgenic mouse after a single intravenous injection. Neuroreport 27(4), 235-241 (2016).

17. Argibay B, Trekker J, Himmelreich $\mathrm{U}$ et al. Intraarterial route increases the risk of cerebral lesions after mesenchymal cell administration in animal model of ischemia. Sci. Rep. 7, 40758 (2017).

18. Meseguer-Olmo L, Montellano AJ, Martínez T et al. Intraarticular and intravenous administration of 99MTc-HMPAO-labeled human mesenchymal stem cells (99MTC-AH-MSCS): in vivo imaging and biodistribution. Nucl. Med. Biol. 46, 36-42 (2017).

19. Yoon JH, Roh EY, Shin S et al. Comparison of explant-derived and enzymatic digestion-derived MSCs and the growth factors from Wharton's jelly. Biomed. Res. Int. 2013, 428726 (2013). 
20. Hua J, Gong J, Meng H et al. Comparison of different methods for the isolation of mesenchymal stem cells from umbilical cord matrix: proliferation and multilineage differentiation as compared to mesenchymal stem cells from umbilical cord blood and bone marrow. Cell Biol. Int. 38(2), 198-210 (2014).

21. Taghizadeh RR, Cetrulo KJ, Cetrulo CL. Collagenase impacts the quantity and quality of native mesenchymal stem/stromal cells derived during processing of umbilical cord tissue. Cell Transplant. 27(1), 181-193 (2018).

22. Schallmoser K, Bartmann C, Rohde E et al. Human platelet lysate can replace fetal bovine serum for clinical-scale expansion of functional mesenchymal stromal cells. Transfusion 47(8), 1436-1446 (2007).

23. von Bahr L, Sundberg B, Lönnies L et al. Long-term complications, immunologic effects, and role of passage for outcome in mesenchymal stromal cell therapy. Biol. Blood Marrow Trans. 18(4), 557-564 (2012).

24. Galipeau J. The mesenchymal stromal cells dilemma - does a negative phase III trial of random donor mesenchymal stromal cells in steroid-resistant graft-versus-host disease represent a death knell or a bump in the road? Cytotherapy 15(1), 2-8 (2013).

25. Moll G, Alm JJ, Davies LC et al. Do cryopreserved mesenchymal stromal cells display impaired immunomodulatory and therapeutic properties? Stem Cells 32(9), 2430-2442 (2014).

26. Chinnadurai R, Copland IB, Garcia MA et al. Cryopreserved mesenchymal stromal cells are susceptible to T-cell mediated apoptosis which is partly rescued by IFN $\gamma$ licensing. Stem Cells 34(9), 2429-2442 (2016).

27. Abazari A, Hawkins BJ, Clarke DM, Mathew AJ. Biopreservation best practices: a cornerstone in the supply chain of cell-based therapies - MSC model case study. Cell Gene Therapy Insights 3(10), 853-871 (2017).

28. Mason C, Brindley DA, Culme-Seymour E, Davie NL. Cell therapy industry: billion dollar global business with unlimited potential. Regen. Med. 6(3), 265-272 (2011).

29. Snyder J, Turner L. Selling stem cell 'treatments' as research: prospective customer perspectives from crowdfunding campaigns. Regen. Med. 13(4), 375-384 (2018).

30. ClinicalTrials.gov. MD, USA: National Library of Medicine (US), Specialized Information Services Division. (2003) https://clinicaltrials.gov/ct2/manage-recs/fdaaa\#WhichTrialsMustBeRegistered

31. International Committee of Medical Journal Editors (ICMJE). (2008) www.icmje.org/about-icmje/faqs/clinical-trials-registration/ 
